\title{
Bariatric surgery and binge eating disorder: should surgeons care about it? A literature review of prevalence and assessment tools
}

\author{
Beatriz H TESS ${ }^{1}$, Letícia MAXIMIANO-FERREIRA², Denis PAJECKI ${ }^{3}$, and Yuan-Pang WANG ${ }^{4}$
}

Received 21/11/2018

ABSTRACT - Background - Eating pathologies among bariatric surgery candidates are common and associated with adverse surgical outcomes, including weight regain and low quality of life. However, their assessment is made difficult by the great variety and inconsistent use of standardized measures. Objective - The purpose of this review was to synthesize current knowledge on the prevalence of binge eating disorder (BED) in presurgical patients and to make a critical appraisal of assessment tools for BED. Methods - A search was conducted on PubMed, Scopus, and Web of Science databases from January 1994 to March 2017. Data were extracted, tabulated and summarized using a narrative approach. Results - A total of 21 observational studies were reviewed for data extraction and analysis. Prevalence of BED in bariatric populations ranged from $2 \%$ to $53 \%$. Considerable variation in patient characteristics and in BED assessment measures was evident among the studies. In addition, several methodological weaknesses were recognized in most of the studies. Ten different psychometric instruments were used to assess BED. Clinical interviews were used in only 12 studies, though this is the preferred tool to diagnose BED. Conclusion - Study heterogeneity accounted for the variability of the results from different centers and methodological flaws such as insufficient sample size and selection bias impaired the evidence on the magnitude of BED in surgical settings. For the sake of comparability and generalizability of the findings in future studies, researchers must recruit representative samples of treatment-seeking candidates for bariatric surgery and systematically apply standard instruments for the assessment of BED.

HEADINGS - Obesity. Bariatric surgery. Binge-eating disorder. Adult. Prevalence. Review.

\section{INTRODUCTION}

Bariatric surgery is now considered the most effective treatment for severe obesity. Reports from randomized controlled trials have indicated positive long-term results in terms of weight loss, resolution of comorbidities and improved life expectancy ${ }^{(1,2)}$. However, although surgery has an important role in the care of patients with severe obesity, some psychopathological features, specifically disordered eating behavior, may jeopardize postsurgical outcomes ${ }^{(3,4)}$. Binge eating disorder (BED) has been claimed as one such behavior ${ }^{(5)}$.

Binge eating symptoms were first noted in 1959 by psychiatrist Albert Stunkard when describing the abnormal eating pattern of a 30-year-old salesman ${ }^{(6)}$, but the American Psychiatric Association has only recently recognized BED as a formal category of psychiatric disorder ${ }^{(7)}$. There is a wide spectrum of clinical manifestations of eating behaviors, from overeating and gluttony to variable binge symptoms until full Diagnostic and Statistical Manual of Mental Disorders 5th edition (DSM-5) BED-criteria are met $^{(8)}$. Therefore, the diagnosis of BED is challenging, due to its complexity and variability in phenotypic presentation $^{(9)}$.

BED is not limited to individuals with obesity but it is most common in this group. Diverse populations have been the target of $B E D$ research. These have comprised samples of individuals with varying degrees of obesity who were identified among the general population, treatment-seeking overweight individuals and those with obesity presenting for bariatric surgery ${ }^{(10-12)}$. The diversity of study populations has contributed to the wide variation in estimates of BED prevalence. A recent meta-analysis estimated that $13 \%$ to $21 \%$ of presurgical patients received a diagnosis of $\mathrm{BED}^{(3)}$, but BED prevalence varied as broadly as $4 \%$ to $49 \%$ in earlier review articles $^{(12-14)}$. The use of heterogeneous diagnostic criteria, study design and assessment methods may explain the wide variation of BED recognition across diverse high-body mass index (BMI) groups.

Although there is conflicting evidence regarding the association between preoperative BED and postoperative weight $\operatorname{loss}^{(3,4,15)}$, today it is generally recommended that treatment should first be directed at disordered eating and associated psychopathology in these patients, before bariatric surgery is indicated ${ }^{(16)}$.

Surgeons and multidisciplinary teams need practical strategies as far as BED diagnoses and treatment in bariatric patients are concerned. Thus there is a real need to focalize and summarize current knowledge on how to practically assess BED in bariatric patients to better inform surgeons and healthcare providers. By improving the diagnosis and treatment of BED, surgery outcomes may be improved in BED-obese bariatric candidates. In this review, we synthesise original studies that aimed at estimating the prevalence of BED among bariatric samples. Then, we use these data to discuss the diverse assessment tools used to measure BED. We conclude with recommendations for the management of bariatric surgery patients and future research.

Declared conflict of interest of all authors: none

Disclosure of funding: Letícia Maximiano Ferreira received scholarship from the Sao Paulo Research Foundation (FAPESP), $n^{\circ}$ 2016/02455-3.

${ }^{1}$ Universidade de São Paulo, Faculdade de Medicina, Departamento de Medicina Preventiva, São Paulo, SP, Brasil. ${ }^{2}$ Universidade de São Paulo, Faculdade de Saúde Pública, Departamento de Nutrição, São Paulo, SP, Brasil. ${ }^{3}$ Universidade de São Paulo, São Paulo, Faculdade de Medicina, Hospital das Clínicas, Disciplina de Cirurgia do Aparelho Digestivo, Departamento de Gastroenterologia, São Paulo, SP, Brasil. ${ }^{4}$ Universidade de São Paulo, Faculdade de Medicina, Hospital das Clínicas, Instituto de Psiquiatria (LIM-23), São Paulo, SP, Brasil.

Corresponding author: Denis Pajecki. E-mail: denis.pajecki@hc.fm.usp.br 


\section{METHODS}

\section{Search strategy and inclusion criteria}

We performed literature searches of three electronic databases (PubMed, Scopus, and Web of Science) applying combinations of the key terms "binge eating disorder", "eating disorder", "obesity", "epidemiology", and "prevalence". The search was delimited to original studies published from 1st January 1994 to 20th March 2017. The lower data limit was chosen in order to include BED provisional criteria in the Diagnostic and Statistical Manual of Mental Disorders, 4th edition (DSM-IV) ${ }^{(7)}$.

To meet the inclusion criteria, the article had to report findings from primary research, address the specific aim of estimating point-prevalence or frequency of BED, report data for adults $(\geq 18$ year-old) with a body mass index (BMI) of at least $30 \mathrm{~kg} / \mathrm{m}^{2}$, assess BED by standardized outcome criteria (i.e., DSM-IV or DSM-5) and be published in English.

Duplicates were removed from the list of 882 retrieved references. Two reviewers (BHT and LMF) independently assessed the information in the remaining 519 articles, to check they met the inclusion criteria. We first looked titles and abstracts then reviewed the full-text articles of 51 selected abstracts. We considered studies irrespective of the type of bariatric surgery. Following consensus on disagreement between reviewers, 21 articles were included in this review.

Parameters for data extraction were established in accordance with the goals of this review. For each article, we collected basic study information (first author, source, year of publication, country, and design), population characteristics (sample size, sex, age, BMI), methods used (diagnostic criteria and methods of outcome assessment) and results (prevalence estimates for total sample). In cases of mixed populations, when bariatric and non-bariatric subgroups were reported, only data relating to bariatric patients were extracted.

\section{Assessment tools}

Assessment methods were retrieved from selected articles and described. Reviewed BED assessment tools from the 21 papers were classified into two groups according to their nature: I) observerrated instruments, or structured clinical interviews, that provided a detailed appraisal of patients' mental health status by trained interviewers; and II) patient-rated instruments, through which subjects self-reported the presence or absence of abnormal eating behavior using an answer sheet or computer screen. Advantages and shortcomings of common measurement tools were discussed in terms of the number of items, content coverage, measurement purpose, psychometric qualities and the number of studies in the present review that have used each tool.

\section{RESULTS}

\section{Characteristics of studies and study samples}

Summary characteristics of the included studies are provided in TABLE 1. All 21 studies $^{(17-37)}$ had a cross-sectional design but presented substantial methodological diversity, including variations in data presentation. For this reason, this review of the literature took the form of a narrative synthesis.

Year of publication was between 1995 and 2016; eight studies $(38 \%)$ were conducted in the $\mathrm{USA}^{(18-22,24,33,37)}$, eight $(38 \%)$ in $\mathrm{Eu}-$ rope $^{(17,23,25-29,31)}$, three $(14 \%)$ in Australia ${ }^{(32,34,35)}$, one $(5 \%)$ in Taiwan ${ }^{(30)}$ and one $(5 \%)$ in Brazil $^{(36)}$. Sample sizes ranged from $50^{(31)}$ to 1283 participants ${ }^{(33)}$. Most studies $(86 \%)$ included individuals of both sexes, with a women/men ratio of around 3:1. Participants' mean age ranged from $34.1^{(30)}$ to 46.2 years $^{(24)}$ and mean BMI from $35.4^{(35)}$ to $54.1 \mathrm{~kg} / \mathrm{m}^{2(20,21)}$.

The DSM-IV criteria for the diagnosis of BED were adopted in all 21 studies. Two also applied the DSM-5 criteria to their population samples in order to compare both classifications $^{(33,34)}$. In terms of use of the instruments to assess BED, 12 studies $(57 \%)^{(17,21,23-26,28-30,32,36,37)}$ only used structured interviews, five $^{(18,19,27,34,35)}$ only self-report questionnaires, and four ${ }^{(20,22,31,33)}$ used both observer-rated interview and self-report questionnaire. Only one ${ }^{(22)}$ compared both methods regarding prevalence of BED, which was as low as $4.2 \%$ for clinical interview but increased more than threefold, to $15.7 \%$, when self-report QEWP-R was used. In four studies ${ }^{(17,22,28,33)}$, there was incomplete information about the clinical interviews that had been applied.

Point-prevalence estimates for BED ranged widely from $2 \%$, based on the DSM-IV criteria applied to a sample of 153 patients $^{(23)}$, to $53 \%$ based on the DSM-5 criteria in a sample of 197 Australian women ${ }^{(34)}$.

\section{Assessment of diagnosis instruments}

TABLE 2 summarizes the characteristics of 10 different types of BED assessment tool identified in the 21 included studies. Most structured interview-based studies used the Structured Clinical Interview for DSM Disorders (SCID). Typically, the application of these structured interviews lasts between 60 and 120 minutes, according to the number of items, which ranged from eight to 28 . While clinician-based structured interviews can be used to diagnose $\mathrm{BED}$, these tools are time-consuming and require previous standardization.

Self-report scale-based studies used a number of instruments to detect eating disorder symptoms [e.g., Binge Eating Scale (BES), Binge Scale (BS), Eating Disorder Examination Questionnaire (EDE-Q), Eating Disorders in Obesity (EDO)], general eating or weight and eating-related symptoms [e.g., Questionnaire on Eating and Weight Patterns (QEWP-R), Eating Disorder Related Quality of Life (QOL-ED)]. The time taken to complete the scales ranges from 5 to 20 minutes, according to the length of the scale (11 to 32 items). These tools can be rapidly administered to screen and monitor eating disorder symptoms in large number of individuals, but do not allow diagnosis of BED. In this review, comparability of tools with similar content coverage, validation, and reliability verification was not consistently observed across included studies.

\section{DISCUSSION}

The prevalence rates of BED in presurgical patients vary widely in the literature and have been reported to be higher than in population-based estimates. In the past 10 years, several review studies have been published with differences in study inclusion and exclusion criteria and have found that prevalence of BED ranged from $6 \%$ to $49 \%{ }^{(3,4)}$. Derived from 21 studies, our prevalence estimates of BED ranged from $2 \%$ to $53 \%$, which is consistent with results from previous publications.

This review confirms that there is a paucity of high-quality evidence regarding $\mathrm{BED}$ in bariatric populations contributing to uncertainty about the validity of study findings. Existing evidence is based on short-term observational studies with widespread methodological weakness. Additionally, variations in the type of 
TABLE 1. Study characteristics and point-prevalence of binge eating disorder in pre-surgery bariatric patients $(\mathrm{k}=21)$.

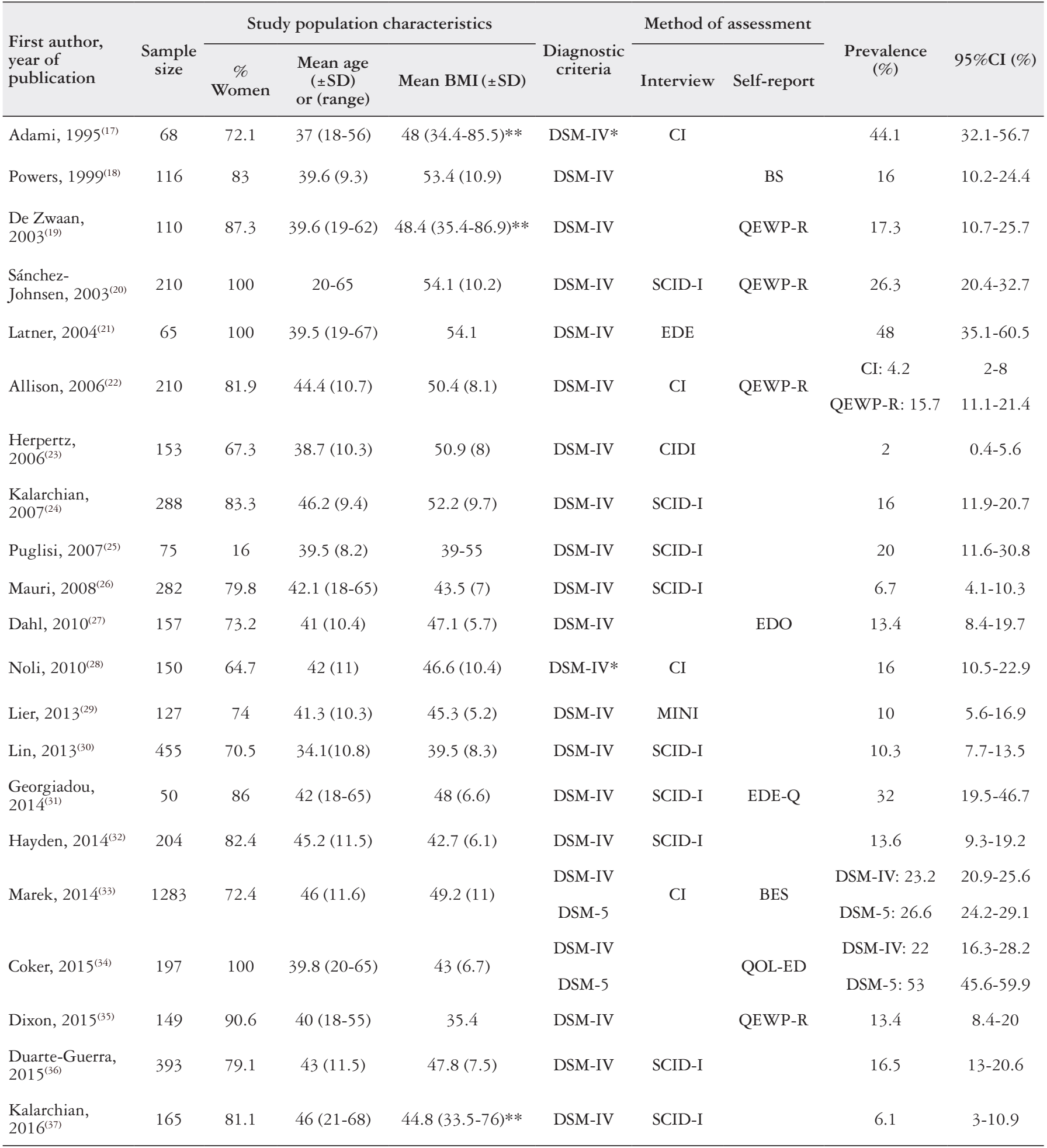

BMI: body mass index, expressed as $\mathrm{kg} / \mathrm{m}^{2}$. SD: standard deviation.

* Spitzer's criteria (1992) were similar to DSM-IV. The "clinical interview" was applied to meet these criteria. ** BMI range (min-max).

EDE: Eating Disorder Examination (version: interviewer-administered); MINI: The Mini International Neuropsychiatric Interview; SCID: Structured Clinical Interview for DSM disorders (versions: SCID-I, SCID-II); CIDI: Composite International Diagnostic Interview; CI: Clinical Interview; BES: Binge Eating Scale; BS: Binge Scale; EDE-Q: Eating Disorder Examination Questionnaire (version: self-administered); EDO: Eating Disorders in Obesity; QEWP: Questionnaire on Eating and Weight Patterns (revised version: QEWP-R); QOL-ED: Eating Disorder Related Quality of life. 
TABLE 2. Characteristics of assessment tools for binge eating disorder used in 21 reviewed studies.

\begin{tabular}{|c|c|c|c|c|c|}
\hline Tools (acronym) & $\begin{array}{l}\text { Number } \\
\text { of items }\end{array}$ & Content coverage & $\begin{array}{l}\text { Measurement } \\
\text { purpose }\end{array}$ & $\begin{array}{c}\text { Number of } \\
\text { studies using } \\
\text { specific tool }\end{array}$ & $\begin{array}{c}\text { Study } \\
\text { (Reference number) }\end{array}$ \\
\hline \multicolumn{6}{|l|}{ Structured interview } \\
\hline $\begin{array}{l}\text { Eating Disorder Examination } \\
\text { (EDE) }\end{array}$ & 28 & $\begin{array}{l}\text { Restraint, eating, weight and shape } \\
\text { concern, plus binge eating frequency } \\
\text { and compensatory behaviors }\end{array}$ & $\begin{array}{l}\text { Specific diagnosis } \\
\text { (eating disorders) }\end{array}$ & 1 & $(21)$ \\
\hline $\begin{array}{l}\text { Mini International } \\
\text { Neuropsychiatry Interview } \\
\text { (MINI) }\end{array}$ & $8^{\dagger}$ & $\begin{array}{l}\text { DSM-based criteria for main } \\
\text { categories of psychiatric diagnosis }\end{array}$ & $\begin{array}{c}\text { Diagnosis } \\
\text { of general } \\
\text { psychopathology }\end{array}$ & 1 & (29) \\
\hline $\begin{array}{l}\text { Structured Clinical Interview } \\
\text { for DSM Axis I disorders } \\
\text { (SCID) }\end{array}$ & $10^{\dagger}$ & $\begin{array}{l}\text { DSM-based criteria for main } \\
\text { categories of psychiatric diagnosis }\end{array}$ & $\begin{array}{c}\text { Diagnosis } \\
\text { of general } \\
\text { psychopathology }\end{array}$ & 9 & $\begin{array}{c}(20,24-26 \\
30-32,36,37)\end{array}$ \\
\hline Binge Scale (BS) & 19 & Behaviors and attitudes of bulimia & Binge symptoms & 1 & (18) \\
\hline $\begin{array}{l}\text { Eating Disorder Examination } \\
\text { Questionnaire (EDE-Q) }\end{array}$ & 32 & $\begin{array}{l}\text { Restraint, eating, weight, and shape } \\
\text { concern }\end{array}$ & $\begin{array}{l}\text { General eating } \\
\text { symptoms }\end{array}$ & 1 & $(31)$ \\
\hline $\begin{array}{l}\text { Eating Disorders in Obesity } \\
\text { (EDO) }\end{array}$ & 11 & $\begin{array}{l}\text { DSM-based assessment for use in } \\
\text { weight loss treatment settings }\end{array}$ & $\begin{array}{l}\text { General eating } \\
\text { symptoms in } \\
\text { obesity }\end{array}$ & 1 & $(27)$ \\
\hline $\begin{array}{l}\text { Questionnaire of Eating and } \\
\text { Weight Patterns - Revised } \\
\text { (QEWP-R) }\end{array}$ & 28 & $\begin{array}{l}\text { Episodes of binge eating, weight } \\
\text { history, body image }\end{array}$ & $\begin{array}{l}\text { Weight and eating } \\
\text { symptoms }\end{array}$ & 4 & $(19,20,22,35)$ \\
\hline $\begin{array}{l}\text { Quality of Life for Eating } \\
\text { Disorders (QOL-ED) }\end{array}$ & 20 & $\begin{array}{l}\text { Domains of behavior, eating and } \\
\text { psychological feelings, effects on daily } \\
\text { life, medical status and body weight }\end{array}$ & $\begin{array}{l}\text { Quality of life } \\
\text { with eating-related } \\
\text { symptoms }\end{array}$ & 1 & $(34)$ \\
\hline
\end{tabular}

DSM: diagnostic and statistical manual for mental disorders, ICD: international classification of diseases. ${ }^{\dagger}$ Specific items for diagnosing binge eating disorder.

assessment tool used make it difficult to identify clear and consistent trends in the prevalence of BED.

Despite the vast number of studies reporting on pre-surgery psychopathological prevalence, no consensus has been reached on the association between preoperative BED and worse weight loss outcomes after surgery. Several studies found that BED may jeopardize weight loss or increase the risk of weight regain ${ }^{(5)}$. Furthermore, some studies have reported that BED-obese individuals need specialized interventions since they tend to have more severe obesity $^{(38,39)}$, poorer surgical outcomes ${ }^{(40)}$, higher rates of mental disorders (such as depression, bipolar, and anxiety) and worse quality of life ${ }^{(41-43)}$ than non-BED-obese people. As a treatable disorder, early identification of BED, together with the treatment of abnormal eating habits must be integrated into routine medical encounters before weight-loss surgery is considered.

The goal of identifying psychological factors that may negatively affect bariatric surgery outcomes is to provide recommendations for intervention before surgery. Therefore, a comprehensive summary of current knowledge on how to assess BED in bariatric candidates is much needed to better inform surgeons about the extent to which under-recognized diagnosis and under-treatment of BED may adversely influence surgery outcomes.

Clinical interview schedules are the gold standard method for the diagnosis of eating disorders. However, their routine application is not always feasible as they are laborious and must be performed by trained mental health professionals. Therefore, self-report questionnaires are preferred as a screening method for the assessment of eating behavior in busy routine clinical conditions. Ideally, a good screening instrument should be highly sensitive in order to identify the majority of affected patients with BED. On the other hand, its specificity is less relevant, since the diagnosis of eating disorders needs to be confirmed by clinical interview.

According to the guidelines for assessment and multidisciplinary follow-up of patients who are candidates for bariatric surgery, the evaluation of mental health is the responsibility of the psychologist or the psychiatrist ${ }^{(16)}$. In practice, the vast majority of services are structured with a psychology team and few use routine psychiatric evaluation. This fact may explain the great variability between the tools used in the diagnosis of eating disorders and the difference in specific attention given to this aspect of psychopathology. We therefore reiterate that the systematic participation of a liaison-psychiatrist in the preoperative evaluation could greatly improve the detection of eating disorders and behaviors, and thus, contribute to a better postoperative result.

Obesity is not a homogeneous condition and it has now been recognized as having a wide variety of phenotype manifestations. Diagnosing pre-surgery eating disorders may help surgeons and health services manage adult bariatric surgery candidates, taking into account this diversity of phenotypes and individualizing treatment procedures. Drawing a parallel with oncological surgery, it 
corresponds to an examination of the image (e.g., computerized tomography scan or magnetic resonance imaging). The bariatric surgeon, in turn, must understand the tools most frequently used and demand standardization of assessment protocols that could provide practical answers to better deal with the surgical patient. In the postoperative follow-up, the surgeon should be able to identify BED and other eating behaviors that may compromise the outcomes of surgery, so that the patient can be referred to the most appropriate treatment. Although in a multidisciplinary team each member has his/her specific vision of the patient, it is up to the bariatric surgeon to have an overall view of what happens to the patient, including his/her mental health status.

\section{CONCLUSION}

The primary objective of BED evaluation is to provide screening and identification of risk factors or potential postoperative challenges that may contribute to a poor postoperative outcome. The ultimate aim of preoperative psychosocial evaluations is to enhance all domains of surgical outcomes. Study heterogeneity may account for the variability in the results from different centers.
Methodological flaws such as insufficient sample size and selection bias curbed the agreed-upon evidence base of the role of BED in the bariatric context. For the sake of comparability and generalizability of the findings in future studies, researchers must prioritize representative samples of treatment-seeking candidates for bariatric surgery and systematically apply criterion-based instruments for the assessment of BED. By using self-report questionnaires, bariatric services would be able to screen a large number of patients, and then confirm the diagnosis of eating disorders by clinical interview.

\section{Authors' contribution}

Tess BH: research execution, text writing. Maximiano-Ferreira L: research execution, data collection. Pajecki D: text writing. Wang YP: research execution. Tess BH and Maximiano-Ferreira L are joint first authors of this work.

\section{Orcid}

Beatriz H Tess. Orcid: 0000-0002-9921-9234.

Letícia Maximiano-Ferreira. Orcid: 0000-0002-6453-1973.

Denis Pajecki. Orcid: 0000-0002-0898-9285.

Yuan-Pang Wang. Orcid: 0000-0001-7076-8312.

Tess BH, Maximiano-Ferreira L, Pajecki D, Wang YP. Cirurgia bariátrica e transtorno de compulsão alimentar: os cirurgiões devem se preocupar com isso? Uma revisão da literatura sobre a prevalência e os métodos de diagnóstico. Arq Gastroenterol. 2019;56(1):55-60.

RESUMO - Contexto - Os transtornos alimentares entre os candidatos à cirurgia bariátrica são comuns e estão associados a resultados cirúrgicos adversos, incluindo recuperação de peso e baixa qualidade de vida. No entanto, sua avaliação é difícil pela grande variedade e uso inconsistente de métodos de avaliação padronizados. Objetivo - O objetivo desta revisão foi sintetizar o conhecimento atual sobre a prevalência do transtorno de compulsão alimentar (TCA) em pacientes pré-cirúrgicos e fazer uma avaliação crítica dos instrumentos de avaliação para TCA. Métodos - A busca foi realizada nas bases de dados PubMed, Scopus e Web of Science de janeiro de 1994 a março de 2017. Os dados foram extraídos, tabulados e resumidos usando uma abordagem narrativa. Resultados - Um total de 21 estudos observacionais foram revisados para extração e análise de dados. A prevalência de TCA nas populações bariátricas variou de $2 \%$ a 53\%. Variações consideráveis nas características dos pacientes e nas medidas de avaliação do TCA foram evidentes entre os estudos. Além disso, várias fragilidades metodológicas na maioria dos estudos foram reconhecidas. Estudos utilizaram 10 diferentes instrumentos psicométricos para avaliar a TCA. Entrevistas clínicas foram utilizadas em 12 estudos, embora seja a ferramenta preferencial para diagnosticar o TCA. Conclusão - A heterogeneidade dos estudos foi responsável pela variabilidade dos resultados nos diferentes centros e falhas metodológicas, como tamanho insuficiente da amostra e viés de seleção, prejudicaram a estimativa da magnitude do TCA em cenários cirúrgicos. Para fins de comparabilidade e generalização dos achados em estudos futuros, os pesquisadores devem recrutar amostras representativas de candidatos à cirurgia bariátrica e fazer a aplicação sistemática de instrumentos padronizados para a avaliação do TCA

DESCRITORES - Obesidade. Cirurgia bariátrica. Transtorno de compulsão alimentar. Adulto. Prevalência. Revisão.

\section{REFERENCES}

1. Leff DR, Heath D. Surgery for obesity in adulthood. BMJ. 2009;339:740-6.

2. O'Brien PE, Hindle A, Brennan L, Skinner S, Burton P, Smith A, et al. Long-term outcomes after bariatric surgery: A systematic review and meta-analysis of weight loss at 10 or more years for all bariatric procedures and single-center review of 20-year outcomes after adjustable gastric banding. Obes Surg. 2019;29:3-14

3. Dawes AJ, Maggard-Gibbons M, Maher AR, Booth MJ, Miake-Lye I, Beroes JM, et al. Mental health conditions among patients seeking and undergoing bariatric surgery: A meta-analysis. JAMA 2016;315:150-63.

4. Livhits M, Mercado C, Yermilov I, Parikh JA, Dutson E, Mehran A, et al. Pre-operative predictors of weight loss following bariatric surgery: Systematic review. Obes Surg. 2012;22:70-89.

5. Meany G, Conceição E, Mitchell JE. Binge eating, binge eating disorder and loss of control eating: Effects on weight outcomes after bariatric surgery. Eur Eat Disord Rev. 2014;22:87-91

6. Stunkard AJ. Eating patterns and obesity. Psychiatr Q. 1959;33:284-95.

7. American Psychiatric Association. Diagnostic and Statistical Manual of Mental Disorders (4th Edition, DSM-IV). APA: Washington, DC; 1994
8. Wilfley D, Citrome L, Herman B. Characteristics of binge eating disorder in relation to diagnostic criteria. Neuropsychiatr Dis Treat. 2016;12:2213-23.

9. Guerdjikova AI, Mori N, Casuto LS, McElroy SL. Binge Eating Disorder. Psychiatr Clin North Am. 2017;40:255-66.

10. Grucza R, Przybeck T, Cloninger R. Prevalence and correlates of binge eating disorder in a community sample. Compr Psychiatry. 2007;48:124-31.

11. Vamado PJ, Williamson DA, Bentz BG, Ryan DH, Rhodes SK, O'Neil PM, et al. Prevalence of binge eating disorder in obese adults seeking weight loss treatment. Eat Weight Disord. 1997;2:117-23.

12. Parker K, Brennan L. Measurement of disordered eating in bariatric surgery candidates: A systematic review of the literature. Obes Res Clin Pract. 2015; 9:12-25.

13. Mitchell JE, King WC, Courcoulas A, Dakin G, Elder K, Engel S, et al. Eating behavior and eating disorders in adults before bariatric surgery. Int J Eat Disord. 2015;48:215-22.

14. Niego SH, Kofman MD, Weiss JJ, Geliebter A. Binge eating in the bariatric surgery population: A review of the literature. Int J Eat Disord. 2007;40:349-59. 
15. van Hout GC, Verschure SK, van Heck GL. Psychosocial predictors of success following bariatric surgery. Obes Surg. 2005;15:552-60.

16. Mechanick JI, Youdim A, Jones DB, Garvey WT, Hurley DL, McMahon M, et al. Clinical practice guidelines for the perioperative nutritional, metabolic, and nonsurgical support of the bariatric surgery patient - 2013 update: Cosponsored by American Association of Clinical Endocrinologists, The Obesity Society, and American Society for Metabolic \& Bariatric Surgery. Surg Obes Relat Dis. 2013;9:159-91.

17. Adami GF, Gandolfo P, Bauer B, Scopinaro N. Binge eating in massively obese patients undergoing bariatric surgery. Int J Eat Disord. 1995;17:45-50.

18. Powers PS, Perez A, Boyd F, Rosemurgy A. Eating pathology before and after bariatric surgery: A prospective study. Int J Eat Disord. 1999;25:293-300.

19. de Zwaan M, Mitchell JE, Howell LM, Monson N, Swan-Kremeier L, Crosby $\mathrm{RD}$, et al. Characteristics of morbidly obese patients before gastric bypass surgery. Compr Psychiatry. 2003;44:428-34

20. Sánchez-Johnsen LAP, Dymek M, Alverdy J, Le Grange D. Binge eating and eating-related cognitions and behavior in ethnically diverse obese women. Obesity. 2003;11:1002-9.

21. Latner JD, Wetzler S, Goodman ER, Glinski J. Gastric bypass in a low-income, inner-city population: Eating disturbances and weight loss. Obesity. 2004;12 956-61.

22. Allison KC, Wadden TA, Sarwer DB, Fabricatore AN, Crerand CE, Gibbons LM, et al. Night eating syndrome and binge eating disorder among persons seeking bariatric surgery: Prevalence and related features. Obesity. 2006;14: 77S-82S.

23. Herpertz S, Burgmer R, Stang A, de Zwaan M, Wolf AM, Chen-Stute A, et al Prevalence of mental disorders in normal-weight and obese individuals with and without weight loss treatment in German urban population. J Psychosom Res. 2006;61:95-103.

24. Kalarchian MA, Marcus MD, Levine MD, Courcoulas AP, Pilkonis PA, Ringham RM, et al. Psychiatric disorders among bariatric surgery candidates: Relationship to obesity and functional health status. Am J Psychiatry. 2007;164:328-34.

25. Puglisi F, Antonucci N, Capuano P, Capuano P, Zavoianni L, Lobascio P, et al Intragastric balloon and binge eating. Obes Surg. 2007;17:504-9.

26. Mauri M, Rucci P, Calderone A, Santini F, Oppo A, Romano A, et al. Axis I and II disorders and quality of life in bariatric surgery candidates. J Clin Psychiatry. 2008;69:295-301.

27. Dahl JK, Eriksen L, Vedul-Kjelsås E, Strømmen M, Kulseng B, Mårvik R, et al. Prevalence of all relevant eating disorders in patients waiting for bariatric surgery: A comparison between patients with and without eating disorders. Eat Weight Disord. 2010;15:247-55.

28. Noli G, Cornicelli M, Marinari GM, Carlini F, Scopinaro N, Adami GF. Alexithymia and eating behaviour in severely obese patients. J Hum Nutr Diet. 2010;23:616-9.
29. Lier HØ, Biringer E, Stubhaug B, Tangen T. Prevalence of psychiatric disorder before and 1 year after bariatric surgery: The role of shame in maintenance of psychiatric disorders in patients undergoing bariatric surgery. Nord J Psychiatry. 2013;67:89-96

30. Lin HY, Huang CK, Tai CM, Lin HY, Kao YH, Tsai CC, et al. Psychiatric disorders of patients seeking obesity treatment. BMC Psychiatry. 2013;13:1-8.

31. Georgiadou E, Gruner-Labitzke K, Kohler H, de Zwaan M, Muller A. Cognitive function and nonfood-related impulsivity in post-bariatric surgery patients. Front Psychol. 2014;5:1-7.

32. Hayden MJ, Murphy KD, Brown WA, O'Brien PE. Axis I Disorders in adjustable gastric band patients: The relationship between psychopathology and weight loss. Obes Surg. 2014;24:1469-75

33. Marek RJ, Ben-Porath YS, Ashton K, Heinberg LJ. Impact of using DSM-5 criteria for diagnosing binge eating disorder in bariatric surgery candidates: Change in prevalence rate, demographic characteristics, and scores on the Minnesota Multiphasic Personality Inventory-2 restructured form (MMPI-2-RF). Int J Ea Disord. 2014;47:553-7.

34. Coker EL, von Lojewski A, GM Luscombe, SF Abraham. The difficulty in defining binge eating in obese women: How it affects prevalence levels in presurgical bariatric patients. Eat Behav. 2015; 17:130-5

35. Dixon JB, Eaton LL, Vincent V, Michaelson R. LAP-BAND for BM 30-40: 5-year health outcomes from the multicenter pivotal study. Int J Obes. 2016;40:291-8

36. Duarte-Guerra LS, Coelho BM, Santo MA, Wang Y-P. Psychiatric disorder among obese patients seeking bariatric surgery: Results of Structured Clinica Interviews. Obes Surg. 2015;25:830-7

37. Kalarchian MA, King WC, Devlin MJ, Marcus MD, Garcia L, Chen JY, et al Psychiatric disorders and weight change in a prospective study of bariatric surgery patients: A 3-year follow-up. Psychosom Med. 2016;78:373-81.

38. Kolotkin RL, Westman EC, Østbye T, Crosby RD, Eisenson HJ, Binks M. Does binge eating disorder impact weight-related quality of life? Obes Res. 2004;12:9991005

39. Nicholls W, Devonport TJ, Blake M. The association between emotions and eating behaviour in an obese population with binge eating disorder. Obes Rev. 2016;17:30-42

40. Bulik CM, Sullivan PF, Kendler KS. Medical and psychiatric morbidity in obese women with and without binge eating. Int J Eat Disord. 2002;32:72-8.

41. Perez M, Warren CS. The relationship between quality of life, binge-eating disorder, and obesity status in an ethnically diverse sample. Obesity. 2012;20:879-85.

42. Costa AJRB, Pinto SL. Binge eating disorder and quality of life of candidates to bariatric surgery. ABCD Arq Bras Cir Dig. 2015;28 (Supll 1):52-5.

43. Ribeiro GANA, Giapietro HB, Belarmino LB, Salgado-Junior W. Depressão, ansiedade e compulsão alimentar antes e após cirurgia bariátrica: problemas que persistem. ABCD Arq Bras Cir Dig. 2018;31:e1356. 